\title{
O acesso à justiça e a realidade da sua gratuidade: uma análise sobre a sua efetividade a partir da Constituição e do CPC
}

\author{
Access to justice and the reality of its gratuity: an analysis of its effectiveness based on the \\ Constitution and the CPC \\ El acceso a la justicia y la realidad de su gratuidad: un análisis de su efectividad con base en la \\ Constitución y el CPC
}

Julia Izabelle Toneto Romano

ORCID: https://orcid.org/0000-0001-6637-5700 Universidade Paranaense, Brasil E-mail: juliaiza@hotmail.com Miriam Fecchio Chueiri ORCID: https://orcid.org/0000-0003-4658-5414 Universidade Paranaense, Brasil Email: mfecchio@prof.unipar.br

Luiz Manoel Gomes Júnior ORCID: https://orcid.org/0000-0002-8111-4549 Universidade Paranaense, Brasil E-mail: luizm@luizmconsultoria.com.br

\begin{abstract}
Resumo
O trabalho tem por objetivo apresentar os principais aspectos relativos ao princípio do acesso à justiça no que diz respeito à realidade de sua gratuidade. Realizou-se, dessa forma, a análise da positivação do acesso à justiça e da assistência jurídica na Constituição Federal e no Código de Processo Civil, a fim de se demonstrar que ainda há ineficiência do acesso à justiça, especificamente quando relacionado à assistência jurídica gratuita, e em especial com relação à Defensoria Pública, tanto nacional, como no Estado do Paraná. Questionou-se, ao final, pontos relacionados ao referido princípio que, acredita-se, não seguem em direção à sua efetividade, e que podem, na verdade, caminhar em sentido oposto à esperada segurança jurídica, bem como à sensação de justiça do jurisdicionado. Para tanto, utilizou-se do método dedutivo, a partir de um conceito geral do princípio do acesso à justiça e a sua particular efetividade quando da análise da gratuidade da justiça. O estudo é pautado também em análise gráfica e documental, além de pesquisa bibliográfica, com objetivo metodológico descritivo e exploratório, valendo-se da obra "O Acesso à Justiça" como referencial teórico, bem como dos anteprojetos da Constituição e as propostas de emendas.
\end{abstract}

Palavras-chave: Acesso à justiça; Assistência jurídica; Defensoria pública; Gratuidade da justiça; CPC/2015.

\begin{abstract}
The work aims to present the main aspects related to the principle of access to justice with regard to the reality of its gratuitousness. Thus, the analysis of the affirmation of access to justice and legal assistance in the Federal Constitution and in the Code of Civil Procedure was carried out, in order to demonstrate that there is still inefficiency of access to justice, specifically when related to free legal assistance, and especially in relation to the Public Defender's Office, both nationally and in the State of Paraná. At the end, it questioned points related to the aforementioned principle that are believed not to move towards its effectiveness, and which may, in fact, move in the opposite direction to the expected legal certainty, as well as to the sense of justice of the jurisdiction. For that, the deductive method was used, from a general concept of the principle of access to justice and its particular effectiveness when analyzing the gratuitousness of justice. The study is also based on graphic and documental analysis, in addition to bibliographical research, with descriptive and exploratory methodological objective, using the work "O Acesso ao Justiça" as a theoretical reference, as well as the drafts of the Constitution and proposals for amendments.
\end{abstract}

Keywords: Access to justice; Legal assistance; Public defense; Free Justice; CPC/2015.

\section{Resumen}

El trabajo tiene como objetivo presentar los principales aspectos relacionados con el principio de acceso a la justicia en relación con la realidad de su gratuidad. Así, se realizó el análisis de la afirmación del acceso a la justicia y la asistencia jurídica en la Constitución Federal y en el Código de Procedimiento Civil, con el fin de demostrar que aún 
existe ineficiencia en el acceso a la justicia, específicamente en lo relacionado con la asistencia jurídica gratuita, y especialmente en relación con la Defensoría Pública, tanto a nivel nacional como en el Estado de Paraná. Finalmente, cuestionó puntos relacionados con el referido principio que se cree que no avanzan hacia su efectividad, y que pueden, de hecho, ir en sentido contrario a la certeza jurídica esperada, así como al sentido de justicia de la ley. jurisdicción. Para ello, se utilizó el método deductivo, a partir de una concepción general del principio de acceso a la justicia y su particular efectividad a la hora de analizar la gratuidad de la justicia. El estudio también se basa en el análisis gráfico y documental, además de la investigación bibliográfica, con objetivo metodológico descriptivo y exploratorio, tomando como referencia teórica el trabajo "O Acesso ao Justiça”, así como los borradores de la Constitución y propuestas de reforma.

Palabras clave: Acceso a la justicia; Asistencia legal; Defensor público; Justicia libre; CPC/2015.

\section{Introdução}

A Constituição Federal de 1988 positivou o que comumente se chama de princípio do acesso à justiça, em seu art. $5^{\circ}$, inc. XXXV, considerado também um direito fundamental, destinado à defesa de posições jurídicas na ordem jurídica e garantidor de todos os demais direitos fundamentais, já que é o que permite o acesso pelo cidadão à tutela jurisdicional.

Muitas são as discussões acerca do acesso à justiça tendo em vista a evidente desigualdade de um país como o Brasil, e a dificuldade em se garantir a equidade dos direitos assegurados constitucionalmente, entre todos os cidadãos.

Por desigualdade deve-se aqui considerar não apenas àquela econômica e financeira, mas também a técnica, de conhecimento, de estudo e de acesso à informação, a que o Estado deve lançar atenção e procurar minorar de maneira eficaz.

Assim, diante da previsão constitucional de acesso à tutela jurisdicional, agregada à todas estas desigualdades e necessidade de minora-las, é que foi primordial garantir o acesso à tutela destes direitos por meio da assistência jurídica e judiciária, de forma gratuita.

Tendo isso em vista, o estudo procurou abranger o aspecto constitucional do princípio do acesso à justiça, considerando seus novos contornos, além de trazer os problemas quanto a sua efetividade relacionados na clássica obra "O Acesso à Justiça” de Mauro Cappelletti e Bryant Garth, utilizada como referencial teórico, e as suas propostas, chamadas de ondas renovatórias.

Em um segundo momento, tendo como base estas concepções, buscou-se fazer a análise da construção história do art. $5^{\circ}$, inc. XXXV, já que este não possui em seu texto a expressão "acesso à justiça", a fim de se compreender qual a motivação do legislador constituinte para assim o fazer.

Analisou-se a assistência jurídica em diversos aspectos, desde a sua criação, até a instituição da Defensoria Pública no país, e a constatação, por meio de gráficos, da insuficiência das mesmas, tanto nacionalmente, como no Estado do Paraná, em relação ao número de habitantes.

Por fim, através de uma leitura crítica, especialmente dos artigos do Código de Processo Civil referentes à gratuidade da justiça, foram levantados alguns questionamentos que permitiram se chegar à conclusão de que, mesmo com os avanços relativos ao tema, o acesso à justiça por meio da sua gratuidade não é efetivo, e algumas disposições são paradoxais, podendo surtir, na verdade, a sensação negativa ao jurisdicionado de injustiça.

\section{Metodologia}

$\mathrm{O}$ artigo avaliou, de maneira crítica, a efetividade e a realidade do acesso à justiça em seu aspecto relativo à gratuidade do sistema, pautando-se, essencialmente, em pesquisa bibliográfica, documental e análise gráfica quanto ao quadro de defensores públicos.

Utilizou-se do método dedutivo, que segundo Eva Maria Lakatos e Marina de Andrade Marconi (2003, p. 92), suas premissas são capazes de sustentar a conclusão em sua totalidade. Assim, parte-se do conceito de princípio do acesso à justiça, 
seu aspecto histórico, criando o caminho a fim de se chegar a problemática referente à sua efetividade quando da análise da gratuidade da justiça.

\section{O Princípio do Acesso à Justiça como Direito Fundamental}

Gilmar Ferreira Mendes e Paulo Gustavo Gonet Branco (2020, p. 528) utilizam a expressão "Direitos fundamentais de caráter judicial e garantias constitucionais do processo", cunhada pela dogmática constitucional alemã (Justizgrundrechte), para se referir a um rol de proteções constantes da Constituição, cujo objetivo é proteger o indivíduo no contexto do processo judicial, apesar de se saber que esses direitos não estão restritos à esfera judicial propriamente dita, mas também se aplicam aos procedimentos administrativos, e até mesmo às relações privadas.

Para além de conceitos e definições já muito comumente conhecidos a respeito dos direitos fundamentais, pretendese aqui ressaltar alguns outros aspectos relevantes, a fim de se conduzir à ideia problema.

A Constituição Federal (CF) de 1988 elenca vários direitos que são destinados à defesa da posição jurídica perante à Administração ou órgãos jurisdicionais em geral, dentre os quais citam-se os incisos XXXIV; XXXV; XXXVII a LXXIV; LXVIII, LXXVI e LXXVIII, todos do art. $5^{\circ}$, inserido no título referente aos direitos e garantias fundamentais.

É preciso destacar ainda que os direitos fundamentais têm sua razão de ser, com o objetivo de dar concretude e consolidação para um dos princípios da República Federativa do Brasil, qual seja, a dignidade da pessoa humana, prevista no inc. III do art. $1^{\circ}$ da Constituição Federal, e que pode ser considerada a "qualidade tida como inerente a todo e qualquer ser humano [...]" e "o valor próprio que identifica o ser humano como tal" (SARLET, 2009, p. 45).

A Convenção Europeia de Direitos Humanos (CEDH) possibilitou a expansão dessas garantias, que foram contempladas pela $\mathrm{CF} / 88$ a fim de ampliar o significado dos direitos fundamentais. Alguns desses direitos reconhecidos na CEDH são o direito ao devido processo legal, especialmente a um processo submetido ao postulado da celeridade (art. 6, 1); o direito à assistência jurídica (art. 6, 3, c), e o direito à assistência gratuita de tradutor ou intérprete (art. 6, 3, e), sendo estes dois últimos, por certo, os de maior interesse no momento.

Traz-se tais informações iniciais no intuito de se ressaltar a força vinculante e de eficácia imediata dos direitos fundamentais, importantes para o desenvolvimento do raciocínio do trabalho. Chama-se atenção, ainda, para o entendimento da doutrina (Mancuso, 2015, livro eletrônico e Mendes; Branco, 2020, p. 228) de que o sujeito passivo dos direitos fundamentais é o Estado, ou seja, o Poder Público é o destinatário precípuo das obrigações decorrentes dos direitos fundamentais, justamente porque possuem como função estabelecer um espaço de imunidade do indivíduo em face dos poderes estatais.

O Acesso à Justiça, como expressão, serve para determinar duas finalidades básicas do sistema jurídico (aquele pelo qual as pessoas podem reivindicar seus direitos e solucionar litígios sob os auspícios do Estado): a primeira, de que o sistema deve ser igualmente acessível a todos, e a segunda, a de que ele deve produzir resultados que sejam individual e socialmente justos (Cappelletti; Garth, 1988, p. 8).

Como princípio, foi constitucionalmente positivado pelo inc. XXXV, do art. $5^{\circ}$ da $\mathrm{CF}$, segundo o qual a lei não excluirá da apreciação do Poder Judiciário lesão ou ameaça a direito.

Já muito bem se firmou a ideia de que o acesso à justiça, atualmente, não é apenas o ingresso ao Judiciário, mas um acesso qualificado, que propicie aos indivíduos o acesso à ordem jurídica justa, ou seja, uma garantia de que todos os titulares de direitos possam ver protegidas suas pretensões pela tutela jurisdicional, de forma eficaz, capaz de salvaguardar suas posições jurídicas.

O princípio do acesso à justiça vem passando por uma renovação em seu sentido, que antes era concebido apenas pelo monopólio estatal, e que ora vai "cedendo espaço à novas ideias e propostas, aderentes à tendencial e crescente desjudicialização dos conflitos”, nas palavras de Rodolfo de Camargo Mancuso (2015, livro eletrônico). 
O Conselho Nacional de Justiça, dentro do que lhe cabe tendo em vista sua competência para zelar pela observância do art. 37 da CF/88, conforme dispõe o art. 103-B, $\$ 4^{\circ}$, II, da CF, delineou essa vontade política de implementar uma renovada concepção de acesso à justiça, quando da edição da Resolução nº 125 (2010), considerando:

que a eficiência operacional, o acesso ao sistema de Justiça e a responsabilidade social são objetivos estratégicos do Poder Judiciário, nos termos da Resolução/CNJ 70, de 18 de março de 2009; que o direito de acesso à Justiça, previsto no art. $5^{\circ}, \mathrm{XXXV}$, da $\mathrm{CF} / 1988$, além da vertente formal perante os órgãos judiciários, implica acesso à ordem jurídica justa; que, por isso, cabe ao Judiciário estabelecer política pública de tratamento adequado dos problemas jurídicos e dos conflitos de interesses, que ocorrem em larga e crescente escala na sociedade, de forma a organizar, em âmbito nacional, não somente os serviços prestados nos processos judiciais, como também os que possam sê-lo mediante outros mecanismos de solução de conflitos, em especial dos consensuais, como a mediação e a conciliação.

$\mathrm{O}$ acesso à justiça tem se tornado o principal foco de todas as partes interessadas na comunidade jurídica, cuja perspectiva de leitura e atenção deve ser voltada ao público que utiliza o sistema. Assim, necessário se questionar o que a expressão "acesso à justiça”" de fato significa pela visão desse público, e coloca-los diretamente no centro do sistema de justiça.

Nesse sentido:

However, the voices in the room have almost invariably been those of academics, lawyers, judges, government representatives, and the like. When voices of the public are heard, they are typically the voices of those who have been involved in the justice system - current litigants or those who have previously used the system in some way. All of these people and groups are clearly important and will ultimately be part of an access to justice solution. However, over that period of time, I have increasingly heard myself saying: "If we ask regular people on the street what they feel and understand about justice and access to it, we might get a very different view. (Trevor, 2014, p. 959).

Portanto, vê-se que houve uma releitura do princípio do acesso à justiça, em que novos contornos existem, novos questionamentos surgem, e novas reflexões são necessárias. Dito isto, importante também trazer em pauta tais questionamentos e delinear alguns traços históricos.

\subsection{O problema do acesso à justiça efetivo}

Nos estados liberais burgueses, nos séculos XVIII e XIX, visualizava-se uma filosofia essencialmente individualista dos direitos, o que refletia nos procedimentos adotados para a solução dos litígios. Significava também que o direito ao acesso à proteção judicial era apenas o direito formal do indivíduo, sob o argumento de que, apesar de o acesso à justiça ser um direito natural, estes não necessitavam da ação do Estado para sua proteção, mas bastava a sua característica de passividade, no sentido de não permitir que eles fossem infringidos por outros (Cappelletti; Garth, 1988, p. 9).

Assim, afastar a pobreza, ou a hipossuficiência das pessoas, para se utilizar plenamente da justiça e suas instituições, não era preocupação do Estado. Além disso, no laissez-faire, só podia obter a justiça aquele que pudesse enfrentar seus custos, e o que não podia, era considerado o único responsável por sua sorte. Logo, a igualdade era apenas formal e não efetiva.

Com o desenvolvimento das sociedades do laissez faire, foram crescendo também as demandas coletivas e sociais, o que permitiu uma transformação em relação aos direitos humanos, deixando para trás o seu caráter egoístico e fazendo-se notar a necessidade de uma atuação positiva do Estado para assegurar o gozo desses direitos (Cappelletti; Garth, 1988, p. 10).

Surge então o estudo de Mauro Cappelletti e Bryant Garth, materializado em sua obra "O Acesso à Justiça", trazendo em pauta os principais movimentos renovatórios do acesso à justiça, divididos então em três "ondas”, que foram uma sucessão cronológica de movimentos realizados na intenção de tornar a justiça mais acessível. 
Na sequência, serão apresentados, em ordem e de forma resumida, os obstáculos apontados pelos autores ao acesso à justiça efetivo, e dentro de cada um deles, os enfoques específicos.

\subsubsection{As custas judiciais}

O primeiro enfoque dado pelos autores é no sentido de que a propositura e andamento de uma demanda é bastante dispendiosa, por mais que seja o Estado o responsável pelo pagamento dos juízes, auxiliares dos cartórios e secretarias, os prédios e outros elementos necessários aos processos, restando grande proporção de custos a serem pagos pelos litigantes, principalmente com honorários advocatícios, sendo notório, no Brasil ou em quaisquer outros países, que os advogados e seus serviços são essencialmente caros (Cappelletti; Garth, 1988, p. 15-16).

O segundo enfoque é sobre as pequenas causas. Isso porque duas são as situações quando o valor da controvérsia é pequeno, se considerado o nível de formalidade do processo: ou as custas judiciais podem ultrapassar o montante dado à demanda, relativo ao direito material buscado, ou elas podem tornar a questão posta em litígio uma futilidade por absorver seu conteúdo (Cappelletti; Garth, 1988, p. 19).

Uma terceira perspectiva agravadora dos custos processuais, é pautada pelos autores no tempo, ou, mais especificamente, na delonga da ação até que se chegue a uma decisão exequível. Os efeitos do prolongamento de um processo podem ser bastante graves, culminando muitas vezes na desistência da parte mais fraca, ou mais pobre, ou na aceitação de acordos por valores ínfimos frente ao que efetivamente teriam direito (Fernandes, 2012, online).

Ainda dentro da perspectiva da primeira onda renovatória proposta por Mauro Cappelletti e Briant Garth, existe um outro fator a ser solucionado, que diz respeito à possibilidade das partes.

\subsubsection{Possibilidade das partes}

O primeiro enfoque aqui tratado é também econômico e financeiro, fazendo-se notório que determinadas pessoas, físicas ou jurídicas, detém maior probabilidade de sustentar uma demanda judicial, por gozarem de uma gama de vantagens estratégicas, ainda que com protelações, justamente por possuir capacidade de arcar com os dispêndios.

Da mesma forma, essa capacidade financeira proporciona uma maior e mais qualificada defesa por parte de um advogado, e consequentemente, a parte mais vulnerável, muitas vezes, fica à mercê, e ainda que se reconheça suas prerrogativas, não é crível que seja capaz de medir as probabilidades de perda ou ganho dentro da esfera judicial. Exemplo disso, segundo os autores, é o fato de os juízes deixarem às partes a tarefa de obter e apresentar as provas, desenvolver e discutir a causa (Cappelletti; Garth, 1988, p. 21).

O segundo enfoque sobre a possibilidade das partes é a aptidão para reconhecer um direito e propor uma ação ou sua defesa. Este ponto está relacionado com as vantagens dos recursos financeiros, diferenças de educação, meio, status social, e de crucial importância na determinação da acessibilidade da justiça. São inúmeras as barreiras que devem ser superadas para que um direito seja reivindicado e superado, a começar pelo reconhecimento da existência de um direito juridicamente exigível, ou seja, a noção de que se tem um direito apto a ser cobrado.

Por sua vez, a falta de conhecimento relaciona-se ainda a um outro problema que é a indisposição psicológica das pessoas a recorrerem a processos judiciais, mesmo aqueles que sabem como encontrar um aconselhamento jurídico qualificado. Existe uma declarada desconfiança nos advogados, especialmente nas classes menos favorecidas, por razões óbvias, como as muitas formalidades, ambientes intimidadores e figuras tidas como opressoras (Cappelletti; Garth, 1988, p. 23).

Uma das conclusões a que se chega, portanto, é no sentido de que a gratuidade da justiça nem sempre vai garantir ou corresponder ao acesso à justiça em sua máxima expressão de acesso à ordem jurídica justa. 
Ainda dentro do problema da possibilidade das partes, outra barreira ao acesso à justiça elucidado por Marc Galanter (1974) e apontado por Mauro Cappelletti e Bryant Garth em sua obra, é o que se denominou de litigantes "habituais", ou seja, aqueles que possuem maior afinidade com demandas judiciais por participarem habitualmente e já conhecerem o funcionamento e as estratégias necessárias, e os litigantes "eventuais", aqueles que não participam das lides com tanta frequência ou nunca participaram.

E por fim, o terceiro fator atravancador do acesso à ordem jurídica justa, consiste nos entraves pertinentes aos interesses difusos. Basicamente, por conta de sua natureza coletiva, o problema é que, ou, por um lado, ninguém tem direito de corrigir a lesão de um direito difuso, ou a recompensa é pequena demais, desproporcional às forças necessárias que o motivem a intentar uma ação (Cappelletti; Garth, 1988, p. 26).

Desses fatores até aqui explicitados, o que mais importa ao presente trabalho é o que diz respeito à gratuidade da justiça e situação econômica e financeira das partes, visto que são o que mais se relacionam com a assistência jurídica gratuita no Brasil.

De mais a mais, da análise de todos esses empecilhos, um ponto padrão pode ser notado: essas obstruções sempre serão mais explícitas quando se tiver observando pela perspectiva do mais pobre, dos autores individuais, em causas pequenas, especialmente se colocado em face aos mais poderosos (Cappelletti; Garth, 1988, p. 28). Isso torna difícil a efetivação dos direitos substantivos em vantagens concretas para as pessoas comuns.

\subsubsection{As soluções práticas para o problema do acesso à justiça - As ondas renovatórias de Mauro Cappelletti e Bryant Garth}

O interesse em resolver os entraves relativos ao acesso à justiça efetivo fez exsurgir as três ondas renovatórias, uma sucessão cronológica de movimentos focados em trazer a melhor solução para tais problemas.

A primeira onda foi a assistência judiciária para os pobres; a segunda dizia respeito às reformas tendentes a proporcionar representação jurídica para os interesses difusos; e o terceiro e mais recente, é o que chamaram os autores de "enfoque de acesso à justiça", porque vai além dos posicionamentos anteriores e propõe-se a atacar as barreiras ao acesso, de maneira mais articulada e compreensiva (Cappelletti; Garth, 1988, p. 31).

A primeira e a terceira onda são as que mais servirão de referencial, tendo em vista a ligação à temática aqui proposta.

Dessa forma, a primeira onda renovatória é justamente a assistência judiciária para os pobres. O auxílio de um advogado em causas judiciais é essencial para que se fale em acesso à justiça de maneira justa, o que normalmente custa caro. O objetivo, portanto, é superar a pobreza, dando ao Estado uma posição ativa na providência judicial aos necessitados (Cappelletti; Garth, 1988, p. 32).

Assim, são desenvolvidos três modelos de prestação assistencial jurídica, desencadeados de movimentos anteriores que continuaram crescendo.

O primeiro sistema, chamado de Judicare, teve apoio nos países da Áustria, Holanda, França e Alemanha Ocidental, e sua principal característica é considerar a assistência judiciária um direito de todos que se enquadrem na lei (Cappelletti; Garth, 1988, p. 35). A finalidade é proporcionar uma defesa e representação condizentes com aquela que teriam caso contratassem um advogado. O Estado então paga profissionais particulares para desenvolverem tal função.

Dado interessante diz respeito ao sistema francês, que adotou o judicare não apenas para alcançar os pobres, mas também algumas pessoas acima do nível de pobreza, além de ser deferida para casos particularmente importantes, independentemente dos rendimentos do litigante (Cappelletti; Garth, 1988, p. 37). 
O sistema judicare, no entanto, apesar de ultrapassar a barreira econômica, não resolve outros grandes problemas, culturais e sociais, como atribuir ao pobre a tarefa de reconhecer seus direitos e procurar auxílio, colocando-os a enfrentar um ambiente dentro do qual podem se sentir intimidados, além de desencorajar os advogados a ajuda-los (Cappelletti; Garth, 1988, p. 38).

O segundo modelo é o do advogado remunerado pelos cofres públicos, e tem como origem o Programa de Serviços Jurídicos do Office of Economic Opportunit, de 1965, vanguarda de uma "guerra contra a pobreza". Seu objetivo é diverso do sistema judicare, consistente em criar escritórios de vizinhança, localizados em comunidades mais carentes, facilitando o contato e minimizando barreiras de classes, cuja função é atender os interesses dos pobres enquanto classe, e muito mais empenhar esforços para conscientizá-los sobre novas prerrogativas e de que os advogados são seus aliados nessa busca (Cappelletti; Garth, 1988, p. 39-40).

E finalmente, o último modelo é a combinação dos dois primeiros, adotado por países como a Suécia e a Província Canadense de Quebec, admitindo que, por terem, ambos, suas limitações, poderiam complementar-se (Cappelletti; Garth, 1988, p. 43).

Essas duas províncias foram as primeiras a oferecerem a possibilidade de se escolher o atendimento por advogados públicos ou particulares. No entanto, o sistema Sueco deu maior ênfase para o Judicare, tendo em vista que os advogados públicos são mantidos pelo Estado em benefício dos indivíduos assistidos, enquanto que em Quebec os escritórios seriam mantidos diretamente pelo governo, não influenciando quão bem sucedidos eles sejam em comparação com os advogados particulares, o que, consequentemente, diminui a tendência de se privilegiar disputas individuais, tratando os pobres como grupo e mobilizando-os a advogar por eles mesmos. Estes de Quebec seriam 'advogados de equipe', mais sintonizados com os problemas dos pobres.

O que chama a atenção nesse modelo combinado é a abertura que propiciou, permitindo aos indivíduos a escolha entre os serviços personalizados de um advogado particular ou de um profissional especializado em equipes e sintonizado com os problemas sociais dos pobres, enquanto classe, de forma que, nas palavras de Cappelletti "tanto as pessoas menos favorecidas quanto os pobres como grupos, podem ser beneficiados (Cappelletti; Garth, 1988, p. 44)."

Cabe mencionar a terceira onda renovatória, que propôs um novo enfoque de acesso à justiça, tal qual hoje se concebe, determinando como finalidades básicas do sistema jurídico a de tutelar os direitos e litígios dos indivíduos de maneira igualitária e acessível a todos, produzindo resultados que sejam individual e socialmente justos.

Por fim, Kim Economides, ainda em 1999, já falava de uma possível quarta onda renovatória, relacionada ao acesso à justiça dos operadores do direito, que se configuraria diante do questionamento de: como estes mesmos têm acesso à justiça? O questionamento surge diante da experiência jurídica que pode cegar as percepções e concepções mais profundas de justiça, interna ou social, ignorando a relação entre justiça civil e justiça cívica. Com isso, novas dimensões éticas seriam expostas nessa quarta onda, trazendo novos desafios especialmente com relação à responsabilidade profissional.

Deve ainda a ser considerado nessa nova onda do acesso à justiça as definições contemporâneas de justiça e a que quer se dar acesso aos cidadãos. A chave é abrir novas perspectivas na definição da própria justiça e inquirir a que tipo de justiça os cidadãos devem aspirar, concentrando-se assim, na perspectiva da oferta, e não mais da demanda. Para tanto, deve ser considerado, por exemplo, o acesso ao ensino do direito e o ingresso nas profissões jurídicas, em um primeiro nível, e em segundo nível, o acesso dos profissionais do direito à justiça, para que de fato o cidadão possa se assegurar de que juízes e advogados estão equipados para fazer justiça (EconomideS, 1999, p. 72-73). 


\subsection{Análise sobre a ausência do termo "acesso à justiça" no art. $5^{\circ}$ da Constituição Federal}

Como mencionado, o princípio do acesso à justiça já é de muito debatido ao longo dos anos, se aperfeiçoando, se aprimorando e renovando suas definições conforme requerem o tempo e as necessidades sociais.

Não obstante, é de se notar que o texto do art. $5^{\circ}$, inc. XXXV da CF, que é o artigo de referência ao princípio do acesso à justiça, não contém o termo "acesso à justiça" de maneira expressa. Na verdade, em toda a Constituição Federal, não existe tal menção literal.

Ao analisar a história da construção da carta magna, verifica-se que já na Fase N, no Substitutivo 1 do Relator, Vol. 235, de agosto de $1987^{1}$, não consta a expressão no texto do que até então era o art. $6^{\circ}$, §4º , que dizia "A lei não poderá excluir da apreciação do Poder Judiciário qualquer lesão ou ameaça a direitos".

Porém, voltando alguns passos na história da constituinte, é possível se deparar com o contrário em alguns documentos, ou seja, a previsão expressa do acesso à justiça, inclusive, relacionado ao exercício dos direitos de ação, como é o caso do Anteprojeto da Comissão Temática da Soberania e dos Direitos e Garantias do Homem e da Mulher de maio de 1987, e do Anteprojeto de Constituição da Comissão de Sistematização de junho de $1987^{2}$, que possuíam a seguinte redação, ressalvadas pequenas alterações de um para outro, como a numeração dos incisos e alíneas:

XIX - A SEGURANÇA JURÍDICA. A) A lei e o Estado garantirão a todos o acesso à justiça e, respeitadas as condições legais, o pleno exercício dos direitos de ação, vedada qualquer restrição ao controle jurisdicional da constitucionalidade; b) a lei não poderá excluir da apreciação do Poder Judiciário nenhuma lesão de direito; [...] y) é dever do Estado prestar assistência judiciária gratuita aos que não podem ter acesso à justiça sem sacrifício do mínimo indispensável à existência digna, nos termos da alínea "b" do inciso I, deste artigo.

Importante ressaltar também a colocação do acesso à justiça dentro do inciso referente à segurança jurídica. A impressão é a de que, na verdade, o inciso tal como se encontra na Constituição Federal, está mais ligado ao princípio da inafastabilidade do controle jurisdicional, no sentido de que nenhuma lei poderá afastar o direito de se exigir do Estado a tutela jurisdicional, do que ao princípio do acesso à justiça, já que este seria mais abrangente do que àquele, não sendo a sua concepção limitada apenas ao ingresso no Poder Judiciário.

Aliás, ao se revolver algumas das emendas ${ }^{3}$ referentes ao dispositivo do "acesso à justiça", verifica-se que as justificativas dos Constituintes ao proporem algum tipo de alteração, comumente se referia à defesa dos direitos e garantias individuais por meio da liberdade de ingresso em juízo.

Tal constatação permite afirmar que a não manutenção da expressão "acesso à justiça" não foi a melhor escolha, ou apenas represente o atraso da Constituição Brasileira em relação ao mundo, se se considerar que à época de sua promulgação a compreensão do acesso à justiça não estivesse ainda tão aguçada e abrangente quanto a que se tem atualmente, inclusive com relação a todas as suas facetas.

Observação também essencial se faz quanto à vinculação da assistência judiciária gratuita como forma de acesso à justiça, dentro do inciso que prevê a segurança jurídica. O que se pode notar é que, invariavelmente, a vontade do legislador era de concedê-la a todos àqueles que não pudessem ter acesso à justiça sem sacrifício do mínimo indispensável à existência digna.

\footnotetext{
1 Projeto de Constituição: Primeiro Substitutivo do Relator. Assembleia Nacional Constituinte. 1987. https://www.camara.leg.br/internet/constituicao20anos/DocumentosAvulsos/vol-235.pdf

2 Anteprojeto de Constituição da Comissão de Sistematização. Assembleia Nacional Constituinte. 1987. https://www.camara.leg.br/internet/constituicao20anos/DocumentosAvulsos/vol-219.pdf

${ }^{3}$ Emendas ao anteprojeto do relator da subcomissão dos direitos e garantias individuais Assembleia Nacional Constituinte. 1987. https://www.camara.leg.br/internet/constituicao20anos/DocumentosAvulsos/vol-79.pdf
} 
Por sua vez, a existência digna consubstanciava-se (e ainda o é) pela garantia ao sujeito de direitos à alimentação, à saúde, ao trabalho e sua remuneração, à moradia, ao saneamento básico, à seguridade social, ao transporte coletivo e à educação, semelhante ao que se vê nos artigos referentes aos direitos sociais do atual texto constitucional.

Ainda, especificamente com relação ao acesso à justiça por meio da sua gratuidade, vai ao encontro dos questionamentos e proposições do artigo, o entendimento do Constituinte Jovanni Masini que propôs, na Emenda no 22407, de setembro de 1987, dar-se o seguinte texto ao $\S 11$ do art. $6^{\circ}$ : "Serão gratuitos todos os atos necessários ao exercício da cidadania, inclusive os de natureza processual e os de registro civil;”. Sua justificativa foi no seguinte sentido:

Trata-se de reincorporar o texto aprovado na subcomissão e na comissão temática. São gratuitos todos os atos, inclusive os de natureza processual e os de registro civil. A gratuidade da justiça está tardando muito a ser adotada entre nós. É o momento de fazê-lo. Se o cidadão não paga pelo funcionamento do parlamento ou pelo expediente do executivo nada além dos tributos com que contribui para a manutenção do Estado, se o cidadão não paga para constituir, através do povo, novos detentores do poder, por que haverá de pagar pelo funcionamento do Poder Judiciário. Isto só faz distanciar o cidadão humilde, que precisa provar que é miserável, humilhando-se, para ter acesso à Justiça. É imprescindível, também, a retirada da expressão "nos termos da lei", que, nesses casos, só faz frustrar o exercício de direito fundamental. A lei não precisa dispor nada. Os atos necessários ao exercício da cidadania, expressão individual da soberania, são gratuitos e basta (CÂMARA DOS DEPUTADOS, 2013, p. 1278).

De fato, o que o cidadão paga para o funcionamento do Legislativo e do Executivo são impostos, não há porque pagar para o funcionamento do Poder Judiciário. No entanto, a emenda foi rejeitada.

$\mathrm{Na}$ verdade, durante a elaboração da Constituição, as previsões referentes ao acesso à justiça sempre estiveram ligadas à assistência judiciária gratuita, o que comprova o exposto anteriormente, no sentido de que, apesar de atualmente existir unanimidade com relação a um amplo acesso à justiça, capaz de se efetivar de inúmeras maneiras, a exemplo dos meios adequados de solução de conflitos, a mesma ideia não é verdadeira quando da elaboração do texto constitucional, que, ao que parece, não teve a proposital intenção de prever um acesso à justiça amplamente, mas sim o princípio da inafastabilidade da jurisdição.

Não se quer com isso afirmar que não existe previsão Constitucional de fato a respeito do princípio do acesso à justiça. Apenas que a escolha por não se fazer constar a expressão no texto da Carta Magna, não parece ter sido motivada, ou intencional, e que os moldes do amplo acesso à justiça e todas as suas perspectivas, tal qual se concebe atualmente, foi, por óbvio, em primeiro lugar uma construção histórica natural, mas também uma construção interpretativa ampliativa do inc. XXXV, do art. $5^{\circ}$, da CF, que foi se estendendo a partir da inafastabilidade da jurisdição até a concepção de efetivo acesso à justiça.

\section{Assistência Jurídica}

Inicialmente, o exercício de julgar era facilmente combinado entre pessoas leigas e profissionais. Todavia, com o tempo, essas funções foram sendo concentradas e especializadas, por meio de grupo de juristas, acadêmicos e membros da administração judiciária, corporações de advogados, juízes e professores de direito, causando impacto crescente nos moldes da justiça (Wolkmer, 2006, p. 363).

Consequências dessa profissionalização foram, primeiro, o fim da gratuidade da justiça, e segundo, o distanciamento das ciências jurídicas do alcance dos leigos, justamente porque se necessitava de um grupo especializado e estudado para esse fim, que não os cidadãos comuns (Wolkmer, 2006, p. 363).

Posteriormente, essas atividades começaram a ser remuneradas, e a partir daí, mais formalismos e burocracias foram se enraizando, até então chegar nos moldes atuais, depois de várias reformas no sistema jurisdicional. 
No Brasil, desde as Ordenações Filipinas existem normas a respeito da assistência gratuita, mas ela ganha garantia de acesso por meio da Lei no 1.060 de 1950, que assegurou a isenção do pagamento das despesas processuais e a possibilidade de contar com defesa técnica por órgãos e pessoas que prestem serviços de forma gratuita, como a Defensoria Pública e os Escritórios de Prática Forense.

O termo "assistência judiciária" foi pela primeira vez expresso em texto constitucional brasileiro, pela Carta da República, de 16 de julho de 1934, em seu art. 113, n. 32. (Moreira, 1992, p. 1). Após, com a Constituição de 1988, o Direito brasileiro assegurou a assistência judiciária gratuita de forma integral aos que comprovarem insuficiência de recursos, por meio do art. $5^{\circ}$, LXXIV.

Foi igualmente constituída, em 1988, a Defensoria Pública, considerada como instituição essencial à função jurisdicional do Estado, nos moldes do art. 134, da CF.

A assistência jurídica gratuita é a porta de acesso à possibilidade de se assegurar todos os demais direitos fundamentais. É por isso que ela existe, para que a efetivação desses direitos não dependa da capacidade econômica do lesado. Nas palavras de Nelson Nery e Georges Abboud "Na realidade, a assistência jurídica gratuita como desdobramento do acesso à justiça é um pressuposto para a efetivação da Constituição propriamente dita” (Nery; Abboud, 2019, livro eletrônico).

Aliás, se dentro dos objetivos da República Federativa, elencados pela Constituição Federal, estão os de "construir uma sociedade livre, justa e solidária" e "erradicar a pobreza e a marginalização e reduzir as desigualdades sociais e regionais", nos termos do art. $3^{\circ}$, inc. I e III), compete então ao Estado diligenciar para que tais objetivos se concretizem, inclusive no que diz respeito ao que mais interesse ao tema, cuidando para que a Defensoria Pública possa promover a assistência jurídica integral e gratuita eficiente.

A leitura do inc. LXXIV, art. $5^{\circ}$ da CF deixa muito claro o que se expôs inicialmente quanto ao sujeito passivo dos direitos fundamentais ser o Estado, pois explicita que "o Estado prestará assistência jurídica integral e gratuita aos que comprovarem insuficiência de recursos".

O Código de Processo Civil de 2015 (CPC), por sua vez, revogou quase que integralmente a Lei 1.060/1950, dispondo sobre a gratuidade da justiça em seus arts. 98 a 102, e logo no caput do primeiro artigo define a abrangência da gratuidade da justiça, afirmando que "A pessoa natural ou jurídica, brasileira ou estrangeira, com insuficiência de recursos para pagar as custas, as despesas processuais e os honorários advocatícios tem direito à gratuidade da justiça, na forma da lei”.

Já de início destaca-se que se consolidou por meio do CPC a possiblidade de concessão de justiça gratuita a pessoas jurídicas. No entanto, a presunção decorrente da mera alegação de insuficiência diz respeito apenas à pessoa natural, nos termos do art. $99, \S 2^{\circ}$.

$\mathrm{O} \S 1^{\circ}$ do art. 98 define o rol das isenções a que compreende a gratuidade da justiça: I - as taxas ou as custas judiciais; II - os selos postais; III - as despesas com publicação na imprensa oficial, dispensando-se a publicação em outros meios; IV - a indenização devida à testemunha que, quando empregada, receberá do empregador salário integral, como se em serviço estivesse; V - as despesas com a realização de exame de código genético - DNA e de outros exames considerados essenciais; VI - os honorários do advogado e do perito e a remuneração do intérprete ou do tradutor nomeado para apresentação de versão em português de documento redigido em língua estrangeira; VII - o custo com a elaboração de memória de cálculo, quando exigida para instauração da execução; VIII - os depósitos previstos em lei para interposição de recurso, para propositura de ação e para a prática de outros atos processuais inerentes ao exercício da ampla defesa e do contraditório; IX - os emolumentos devidos a notários ou registradores em decorrência da prática de registro, averbação ou qualquer outro ato notarial necessário à efetivação de decisão judicial ou à continuidade de processo judicial no qual o benefício tenha sido concedido. 
Ponto interessante trazido pelo CPC foi a possibilidade de a gratuidade da justiça dizer respeito a apenas um ou alguns dos atos processuais, conforme dispõe o art. $98, \S 5^{\circ}$, além da flexibilização em relação ao pagamento das despesas, como a redução percentual, trazida pelo mesmo dispositivo, segunda parte, ou o parcelamento, nos termos do art. 98 , $\S 6^{\circ}$.

Os honorários periciais serão também suportados pelo Estado, conforme determina o art. 95 , $\S 3^{\circ}$ a $5^{\circ}$. No entanto, a concessão de gratuidade não afasta a responsabilidade do beneficiário pelas despesas processuais e pelos honorários advocatícios decorrentes de sua sucumbência, conforme disciplina o $\$ 2^{\circ}$ do art. 98 , e nem de pagar, ao final, as multas a que for condenado, nos termos do $\S 4^{\circ}$ do mesmo artigo.

No caso de ser o beneficiário vencido, as obrigações decorrentes de sua sucumbência ficarão sob condição suspensiva de exigibilidade e somente poderão ser executadas se, nos 5 (cinco) anos subsequentes ao trânsito em julgado da decisão que as certificou, o credor demonstrar que deixou de existir a situação de insuficiência de recursos que justificou a concessão de gratuidade, extinguindo-se, passado esse prazo, tais obrigações do beneficiário.

Essas definições iniciais são importantes para a compreensão dos questionamentos postos nos tópicos subsequentes.

\section{Defensoria Pública}

O dever fundamental de prestação de assistência jurídica integral e gratuita àqueles que, comprovadamente, não possuam recursos suficientes, nos termos do art. $5^{\circ}$, inc. LXXIV, foi imputado ao Estado, o que representa uma das formas de se garantir o acesso à justiça.

Assim, foi criada a Defensoria Pública (DP), que nos termos do art. 134, é instituição permanente, essencial à função jurisdicional do Estado, incumbindo-lhe, como expressão e instrumento do regime democrático, fundamentalmente, a orientação jurídica, a promoção dos direitos humanos e a defesa, em todos os graus, judicial e extrajudicial, dos direitos individuais e coletivos, de forma integral e gratuita, aos necessitados, na forma do inciso LXXIV do art. $5^{\circ}$ desta Constituição Federal.

Todavia, tal instituição não é suficiente para alcançar toda a demanda existente, sendo que, por este motivo, a assistência judiciária se estendeu a prestação de serviço do advogado particular, cadastrado em convênio de cada Estado, firmado com a Ordem dos Advogados do Brasil (OAB).

Há ainda os Juizados Especiais Cíveis e Criminais, regidos pela lei 9.099/1995, previstos no art. 98 da CF, que também garantem a assistência judiciária gratuita, baseando-se em princípios como a oralidade, celeridade, simplicidade e informalidade, que dispensa, inclusive, a presença de advogado, por meio de seu art. $9^{\circ}$, nas causas de valor inferior a vinte salários mínimos.

Entende-se que a tendência é que, com o tempo, haja uma expansão de sistemas, ou leis como a dos juizados especiais, tendo em vista a insuficiência das DP. Os juizados especiais, não obstante, são também, atualmente, grande pauta de estudos, tendo em vista ser um dos grandes estimuladores de litigiosidade no país, justamente por conta da sua gratuidade.

Todavia, entende-se que tal justificativa não deve ser considerada de forma isolada, agregando-se a ela diversos outros fatores, como a falta de informação ao cidadão sobre seus direitos ou a inexistência deles, ou a disseminação equivocada dessas informações. Relembre-se, quanto a este ponto, o que Kim Economides (1999, p. 72-73) aduz com relação à quarta onda renovatória e o acesso à justiça, em primeiro nível, por meio do acesso aos cidadãos ao ensino do Direito.

Ressalta-se que, conhecidamente, a prática jurídica é essencialmente diferente do que se aprende no ensino jurídico, não apenas no âmbito do Poder Judiciário, mas também com relação a instituições públicas, cartórios, órgãos, e tudo que se relaciona ao extrajudicial.

Portanto, problemas desta envergadura justificam um olhar atento ao acesso à justiça pela oferta, e não pela demanda, assim como justificam a necessidade da sua gratuidade, a fim de se possibilitar, de forma efetiva, o acesso à justiça. 


\subsection{Quadro de defensores públicos no brasil}

Um artigo publicado no ano de 2020 mostrou que faltam defensores em quase todas as entidades federativas, sendo o Paraná o Estado com menos Defensores Públicos se comparados ao número total de habitantes.

A pesquisa foi realizada pelo site de estudos, artigos e notícias Migalhas, e apresentou os seguintes Gráficos:

Gráfico 1 - Número de Habitantes por Defensor.

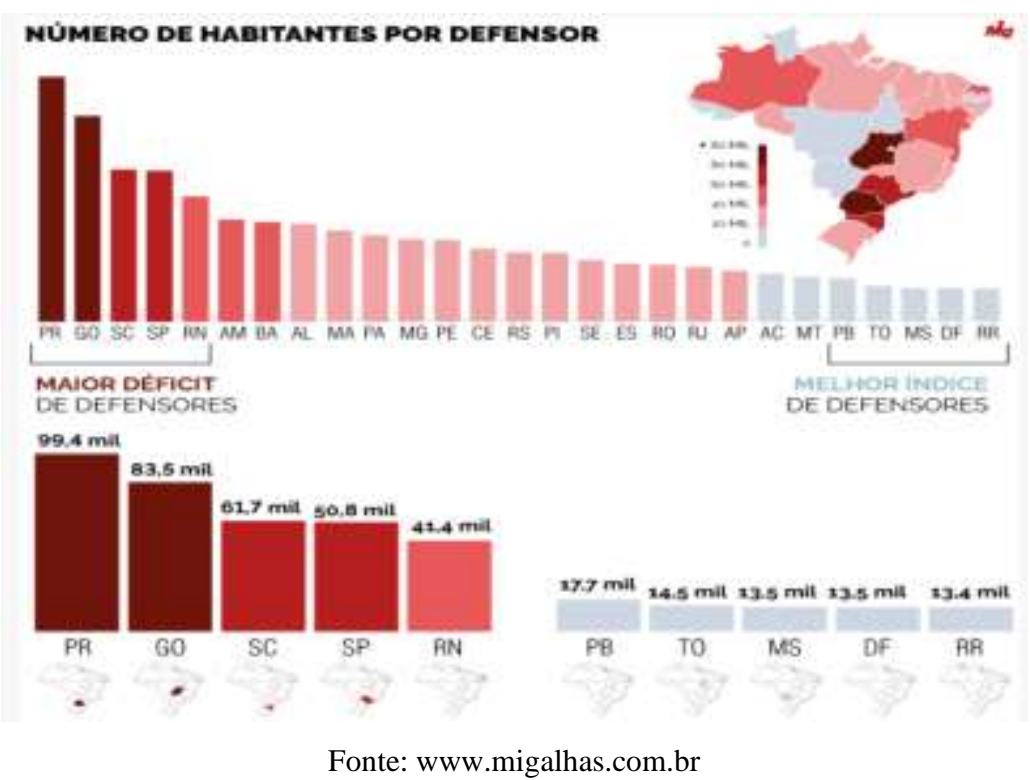

Em dados coletados pela Associação Nacional das Defensoras e Defensores Públicos (ANADEP), em 20184, o Brasil possuía 5.961 defensoras e defensores públicos estaduais em atividade, número muito aquém do necessário para atender toda a demanda existente - cerca de 88\% da população, conforme pesquisa do Instituto Brasileiro de Geografia e Estatística (IBGE).

Ainda, de acordo com O IV Diagnóstico da Defensoria Pública no Brasil ${ }^{5}$ do Ministério da Justiça, de 2015, o ideal é um(a) defensor(a) público(a) para atender cada grupo de 15 mil pessoas, adotando apenas o critério do rendimento.

Como solução para tais números, a ANADEP e APADEP defendem a efetivação da Emenda Constitucional 80/2014, que tem por objetivo universalizar o acesso à Justiça e lotar todas as comarcas do país de defensoras e defensores públicos até o ano de $2022^{6}$.

\subsection{Quadro de defensores públicos no Estado do Paraná}

O site da Defensoria Pública do Paraná mostra, por meio de um mapa do Estado, as cidades em que há atuação:

\footnotetext{
${ }^{4}$ https://www.apadep.org.br/wp-content/uploads/2018/11/book-defensoria-pu\%CC\%81blica.pdf.

${ }^{5}$ IV diagnóstico da Defensoria Pública no Brasil. Org. Gabriella Vieira Oliveira Gonçalves. Brasília: Ministério da Justiça, Secretaria de Reforma do Judiciário, 2015. 138 p.

${ }^{6}$ https://www.apadep.org.br/wp-content/uploads/2018/11/book-defensoria-pu\%CC\%81blica.pdf.
} 
Research, Society and Development, v. 11, n. 1, e42611125121, 2022

(CC BY 4.0) | ISSN 2525-3409 | DOI: http://dx.doi.org/10.33448/rsd-v11i1.25121

Gráfico 2 - Cidades em que há atuação da Defensoria Pública.

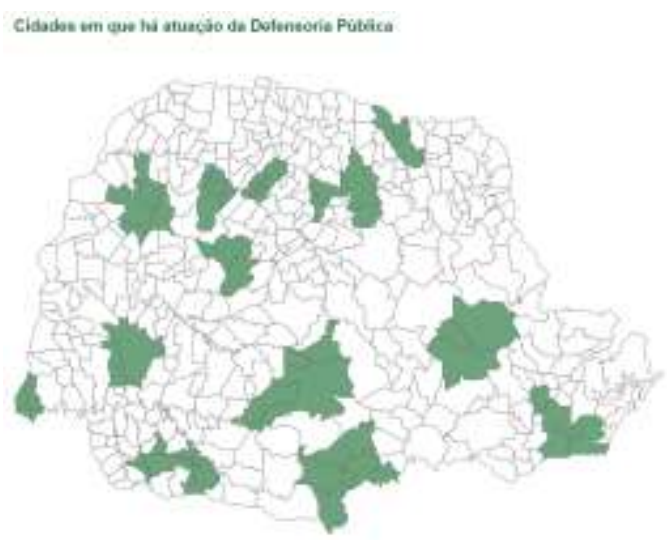

Fonte: www.defensoriapublica.pr.def.br

Das 399 cidades do Estado do Paraná, apenas 57, que estão assinaladas em verde, possuem DP, o que por si só já comprova o déficit do Estado. No entanto, para corroborar, o gráfico a seguir mostra o número de defensores públicos por número de habitantes:

Gráfico 3 - No de habitantes por defensor em cada entidade federativa:

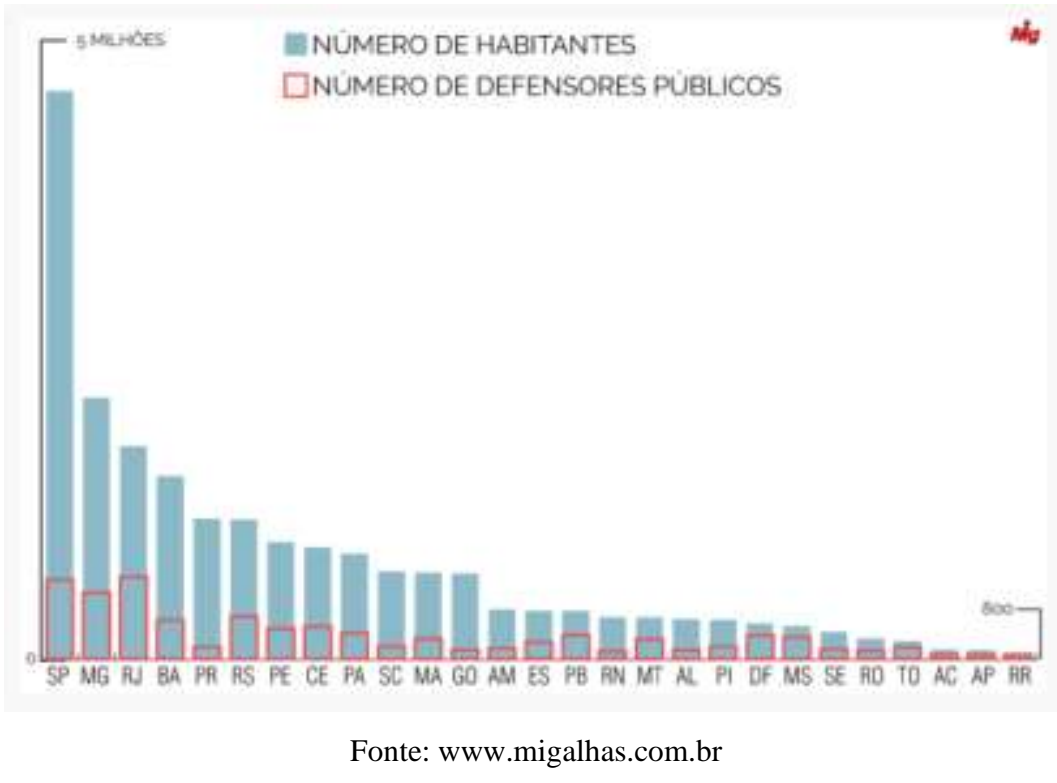

Ainda, os dados coletados pela ANADEP, informam ainda que em 2018, o Estado do Paraná possuía 94 Defensores Públicos. $^{7}$

Tais dados, tanto com relação ao país, como ao Paraná, demonstram a inefetividade do acesso à justiça quando se trata da realidade de sua gratuidade. Não se quer dizer com isso que não há evolução, mas sim que a acesso à justiça quando diz respeito à gratuidade judiciária, ainda está muito aquém da demanda, assim como de alcançar a meta a ser cumprida até 2022.

${ }^{7}$ https://www.apadep.org.br/wp-content/uploads/2018/11/book-defensoria-pu\%CC\%81blica.pdf. 


\section{A realidade do acesso à justiça e a sua gratuidade}

Diante do contexto colocado ao longo deste trabalho, algumas reflexões acerca do acesso à justiça e a realidade de sua gratuidade, são necessárias.

O primeiro deles é justamente com relação a qualificação dos serviços jurídicos. Como não existem defensorias públicas em todas as localidades, e as que existem não são suficientes, exerce-se a assistência jurídica gratuita por meio do convênio com a OAB. Entretanto, não é fato desconhecido que os advogados não dão a mesma atenção e dedicação na atuação da advocacia dativa como em seus casos particulares, e em verdade sabe-se que a maioria se utiliza, por exemplo, da negativa geral.

Também se coloca sob análise reflexiva a ideia de que, atualmente, o grande problema do país é com relação ao acesso à justiça pós ingresso no Poder Judiciário, isto é, a dificuldade encontrada em se ter um desfecho processual que englobe uma decisão qualificada, que de fato cumpra o conceito de acesso à justiça em seus dois aspectos, tratados acima: um sistema igualmente acessível a todos, e que produza resultados que sejam individual e socialmente justos.

Não sem motivo a doutrina brasileira já vêm tratando do problema do acesso à justiça, mas já quando dentro do processo, dada sua dificuldade de término, ou como tem denominado a doutrina, os 'outputs', e não mais em seu aspecto de 'entrada', ou seja, os 'inputs':

...impende ainda não descurar que a resposta jurisdicional, ademais de despojada de dilações excessivas, deve ainda ser justa e tecnicamente consistente, pois, do contrário, se arrisca a trocar um problema por outro: a morosidade excessiva substituída pela "injustiça célere (MANCUSO, 2015, livro eletrônico).

Este argumento está muito mais relacionado com aspectos qualitativos do que quantitativos, sem se desprezar, por óbvio, que a quantidade de demandas processuais no país ainda é um problema não solucionado, mas mais do que isso, relaciona-se o problema com a parte 'justa' do acesso, englobando aí a qualidade das petições iniciais, das decisões, e o tempo razoável.

Quanto à realidade da gratuidade da justiça, outro aspecto deve ser considerado: o art. 98 do CPC dispõe que, sendo a parte beneficiária sucumbente, ela gozará de suspensão por tempo temporária por 5 anos. Havendo alteração superveniente na condição financeira do assistido, poderá ser cobrado então dele os gastos processuais. Significa dizer que a máquina judiciária vai ser movimentada novamente, depois de cinco anos, isto é, durante todo este período vai ser preciso fiscalizar se a situação financeira da pessoa se alterou, para então, em caso positivo, cobrar-se as despesas processuais, corrigidas. É o mesmo argumento que se utiliza pra cobrar as despesas quando se entra com um processo, qual seja, de que se está movimentando a máquina judiciária, porém, para usar em benefício do poder público.

Nesse sentido, questiona-se: qual o incentivo que está se dando pra que haja um crescimento financeiro à essa pessoa, que antes necessitou desse benefício? A premissa é, então, dar benefícios assistenciais pra depois cobrar de volta, dentro de um período de tempo dito razoável. É quase o mesmo que conceder benefício previdenciário a quem sofreu determinada doença temporariamente, e depois cobrá-la para que pague de volta, caso, nesse tempo, tenha cessado seu problema.

Ainda, qual é a extensão da responsabilidade desse sucumbente, de vir até o processo, em até cinco anos e informar sua nova situação financeira? Ou da parte adversa de fazer o mesmo, e ainda trazer provas? Quais são as delimitações dessa “alteração superveniente”? 
É claro que para um benefício que é tão imbuído de aspectos subjetivos, não há de se estabelecer critérios numéricos matemáticos para aferir tal alteração superveniente. Todavia, também não há de se deixar totalmente ao arbítrio, igualmente subjetivo, do juiz.

Soma-se a isto, a falta de equidade, ponderação e razoabilidade no momento de se conceder ou não a gratuidade da justiça ao demandante. Cada vara e cada juiz parece ter uma concepção própria de quem merece ou não receber a benesse, o que deixa, mais uma vez, o cidadão entregue à sorte de uma distribuição do processo que lhe favoreça.

Não são raros os casos em que deixam de demandar por seus direitos, ainda que comprovados, por um receio de, talvez, não conseguir uma decisão que lhe conceda o benefício, ou por não compensar o prejuízo do direito material em vista do prejuízo que poderá amargar com o pagamento de custas processuais. Não se pode também olvidar situações em que a parte cogita desistir do processo por não conseguir o benefício de maneira integral, mesmo fazendo jus a ele, preferindo pagar somente as custas iniciais e suportar o prejuízo da lesão a seu direito.

Assim, os inadimplementos, as ilegalidades dos contratos de massa, as injustiças cometidas pelos litigantes habituais, os danos morais, continuarão por existir, enquanto a grande preocupação estiver voltada em conceder ou não justiça gratuita ao demandante.

Que fique claro que a opinião aqui externada não diz respeito àqueles casos em que a parte não possui, escrachadamente, o direito ao benefício da gratuidade da justiça.

A parte carecedora, ao procurar a justiça, deveria se preocupar tão somente se o profissional a que está colocando suas causas em mãos é qualificado ou não para tratar do seu direito. A partir do momento em que ela tem que escolher entre pagar um advogado para buscar a tutela jurisdicional de forma qualificada, mas com o risco de ter que pagar custas e despesas processuais, ou ficar silente e não exercer seu direito de ação, suportando o prejuízo da lesão sofrida, este direito está automaticamente infringido, e, por consequência, também o está o seu acesso à justiça.

A parte, ao invés de ter que pensar em pagar custas e taxas judiciárias, poderia investir em advogado qualificado, que dedicaria a pensar o melhor caminho para o caso concreto, seja por meios extrajudiciais, o que diminuiria o aspecto quantitativo dos processos, seja por meios judiciais, e então de maneira sempre mais qualificada, traçando as melhores estratégias para o seu bom desenvolvimento, o que também impactaria positivamente no aspecto qualitativo do processo, bem como os aspectos atuais do acesso à justiça.

\section{Conclusão}

O princípio do acesso à justiça, à medida em que a sociedade evolui, ganha novos contornos, e deve também ter suas definições atualizadas. Assim como já não é hoje o que era à época da promulgação da Constituição Federal.

Necessário, portanto, que a perspectiva de análise seja alterada da demanda para a oferta, com questões relativas a que tipo de justiça os cidadãos devem aspirar, ou como é o acesso à justiça pelos profissionais do Direito, e dessa forma, comparar se a realidade do jurisdicionado está sendo de fato considerada por estes, já que muitas vezes aqueles que decidem quem tem o direito de ação, ou quem tem o direito ao benefício da gratuidade da justiça, não se atentam à realidade daqueles que demandam, ou tampouco se preocupam com este aspecto.

Exclusivamente quanto à realidade do acesso à justiça em relação à sua gratuidade, o que se percebe é que está longe de ser considerado efetivo, seja porque não há defensorias públicas suficientes para atender a demanda no país, ou devido às questões enfrentadas na prestação de serviços quando por meio do convênio com a OAB.

No que diz respeito à previsão pelo Código de Processo Civil quanto ao benefício da assistência jurídica gratuita, entende-se que, apesar de seus avanços, como a positivação da possibilidade de concessão à pessoa jurídica, também trouxe 
situações, no mínimo, paradoxais, que podem, à primeira vista, parecer justas, mas que na prática, pode causar a inflação da sensação, pelo jurisdicionado, de injustiça.

Em conclusão, acredita-se que grandes passos já foram dados a fim de se garantir cada vez mais o acesso à justiça efetivo. Todavia, a concessão do benefício da assistência judiciária gratuita, induz a uma falsa perspectiva de garantia deste acesso.

Assim, sugere-se para os próximos estudos, uma análise prática da gratuidade da justiça, especialmente com relação aos artigos trazidos com o Código de Processo Civil de 2015 e sua aplicação real em cada estado, por cada juízo e seus entendimentos e portarias internas, bem como a análise das respectivas jurisprudências dos tribunais.

\section{Referências}

Associação Nacional das Defensoras e Defensores Públicos; Associação Paulista de Defensores Públicos (2018). Apresentando a Defensoria Pública: retrato de uma instituição em desenvolvimento. Brasília.

Anteprojeto de Constituição da Comissão de Sistematização (1987). Assembleia Nacional Constituinte.

https://www.camara.leg.br/internet/constituicao20anos/DocumentosAvulsos/vol-219.pdf.

IV diagnóstico da Defensoria Pública no Brasil (2015). Org. Gabriella Vieira Oliveira Gonçalves. Brasília: Ministério da Justiça, Secretaria de Reforma do Judiciário.

Câmara dos Deputados (2013). A construção do artigo $5^{\circ}$ da Constituição de 1998 [recurso eletrônico]. Brasília: Câmara dos Deputados, Edições Câmara, p. 1278. - (Série obras comemorativas. Homenagem; n. 9).

Cappelletti, M.; Garth, B. (1988) Acesso à justiça. Tradução de Ellen Gracie Northfleet. Porto Alegre: Fabris.

Conselho Nacional de Justiça. (2010). Resolução no 125, de 29 de novembro de 2010. https://www.cnj.jus.br/wp-content/uploads/2011/02/Resolucao_n_125GP.pdf.

Constituição da República Federativa do Brasil (1988). http://www.planalto.gov.br/ccivil_03/constituicao/constituicao.htm.

Economides, K. (1999). Lendo as ondas do "Movimento de Acesso à Justiça”: epistemologia versus metodologia? In Cidadania, justiça e violência/ Organizadores Dulce Pandolfi [et al]. Rio de Janeiro: Ed. Fundação Getulio Vargas, 1999. 248p.

Emendas ao anteprojeto do relator da subcomissão dos direitos e garantias individuais (1987). Assembleia Nacional Constituinte https://www.camara.leg.br/internet/constituicao20anos/DocumentosAvulsos/vol-79.pdf.

Fernandes, D. C. et. al. (202). Estudo crítico acerca da obra acesso à justiça. Monte Carmelo. http://www.fucamp.edu.br/editora/index.php/praxis/article/view/258/217.

Galanter, M. (1974). Why the "haves" come out ahead: speculations on the limits of legal change. Law \& Society Review, vol. 9, n. 1, p. 95-160. http://www.unr.edu/justicestudies/Links1/JS710/JS710Frymer14/3053023.pdf.

Lakatos, E. M. \& Marconi, M.A. (2003). Fundamentos de Metodologia Científica. São Paulo: Atlas.

Lei no 13.105, de 16 de março de 2015. Institui o Código de Processo Civil. Diário Oficial da União, Brasília, DF, 17 março 2015. http://www.planalto.gov.br/ccivil_03/_ato2015-2018/2015/lei/113105.htm.

Mancuso, R. de C. (2015). Acesso à Justiça [livro eletrônico]: condicionantes legítimas e ilegítimas. São Paulo: Revista dos Tribunais.

Mendes, G. F.; Branco, P. G. G. (2020). Curso de Direito Constitucional. 15 ed. São Paulo: Saraiva Educação.

Moreira, J. C. B. (1992). O Direito à Assistência Jurídica: Evolução no Ordenamento Brasileiro de Nosso Tempo. Revista dos Tribunais. v. 67. p. 124-134.

Nery, N.; Abboud, G. (2019). Direito Constitucional Brasileiro [livro eletrônico]. 2 ed. São Paulo: Thomson Reuters Brasil.

Projeto de Constituição: Primeiro Substitutivo do Relator (1987). Assembleia Nacional Constituinte. https://www.camara.leg.br/internet/constituicao20anos/DocumentosAvulsos/vol-235.pdf.

Sarlet, I. W. (2009). Dignidade da Pessoa Humana e Direitos Fundamentais na Constituição Federal de 1988. 7.ed. ver. atual. Porto Alegre: Livraria do Advogado.

Trevor, C. W. F. (2014). What is Acess to Justice?. Osgoode Hall Law Journal 51.3: 957-988. http://digitalcommons.osgoode.yorku.ca/ohlj/vol51/iss3/10.

Wolkmer, A. C. (Org.). (2006). Fundamentos de história de direito. Belo Horizonte: Del Rey. 